\title{
A comparison study of corneal topographic changes following 20-, 23-, and 25-G pars plana vitrectomy
}

\author{
Um estudo comparativo das alterações topográficas da cornea após a vitrectomia via pars plana \\ com 20, 23 e 25 gauge
}

Alexandre Achille Grandinetti ${ }^{1}$, Vinicius Kniggendorf ${ }^{1}$, Luciane Bugmann Moreira ${ }^{1}$, Carlos Augusto Moreira Junior ${ }^{1}$, Ana Tereza Ramos Moreira ${ }^{1}$

\begin{abstract}
Purpose: To evaluate and compare corneal topographic changes following pars plana vitrectomy with the 23-gauge $(G)$ and $25-G$ transconjuntival sutureless vitrectomy system as well as the standard 20-G vitrectomy system.

Methods: We prospectively evaluated corneal topographic changes in 45 eyes of 45 patients divided into three groups according to vitrectomy system used (20-, 23-, and 25-G). All patients underwent computer-assisted videokeratography using an EyeSys System 3000 topographer preoperatively and at one week, one month, and three months postoperatively.

Results: In the 20-G vitrectomy group, we found statistically significant postoperative changes in corneal curvature parameters with an average steepening of $0.98 \pm 0.18 \mathrm{D}(P<0.001)$ and $0.93 \pm 0.21 \mathrm{D}(P<0.001)$ at one week and one month respectively. No statistically significant difference was observed at the three-month follow-up visit. In the 23- and 25-G groups, no statistically significant changes in corneal curvature parameters were observed at any postoperative follow-up visit.

Conclusion: Twenty-three-gauge and 25-gauge transconjunctival sutureless vitrectomy did not induce topographic corneal changes following surgery, whereas 20-G vitrectomy was found to induce transient topographic corneal changes that had returned to preoperative levels at three months postoperatively
\end{abstract}

Keywords: Retina; Vitrectomy; Cornea; Corneal topography; Astigmatism

\section{RESUMO}

Objetivos: Avaliare comparar as alterações topográficas da córnea após a vitrectomia via pars plana com o sistema transconjuntival sem suturas de 23 gauge (g) e $25 \mathrm{~g}$ e com o sistema tradicional de vitrectomia via pars plana $20 \mathrm{~g}$.

Método: Neste estudo prospectivo, as alterações topográficas da córnea foram avaliadas em 45 olhos de 45 pacientes, divididos em 3 grupos de acordo com o sistema de vitrectomia utilizado $(20,23$ e $25 \mathrm{~g})$. Todos os pacientes foram submetidos a topografia corneana computadorizada utilizando-se o topógrafo EyeSys System 3000 antes da cirurgia, e com 1 semana, 1 mês e 3 meses após a cirurgia.

Resultados: No período pós-operatório, no grupo de vitrectomia $20 \mathrm{~g}$, foram encontradas alterações estatisticamente significativas nos parâmetros da curvatura corneana estudados, com um aumento médio da curvatura de 0,98 $\pm 0,18 D(p<0,001)$ e 0,93 $\pm 0,21 \mathrm{D}(p<0,001)$ após uma semana, e um mês, respectivamente. Não se observou diferença estatisticamente significativa na visita realizada 3 meses após a cirurgia. Nos grupos 23 g e 25 g, não se observaram alterações estatisticamente significativas nos parâmetros da curvatura corneana em nenhum dos momentos analisados no pós-operatório.

Conclusão: A vitrectomia transconjuntival sem suturas $23 \mathrm{~g}$ e $25 \mathrm{~g}$ não induziu alterações topográficas da córnea após a cirurgia, enquanto que a vitrectomia $20 \mathrm{~g}$ induziu alterações topográficas da córnea transitórias que retornaram aos níveis pré-operatórios três meses após a cirurgia.

Descritores: Retina; Vitrectomia; Córnea; Topografia corneana; Astigmatismo

\section{INTRODUCTION}

The refractive surface of the cornea is responsible for more than two-thirds of the optical power of the eye. Visual performance can be significantly affected when corneal shape or regularity is subjected to change. Corneal curvature changes induced following vitrectomy and scleral buckling are well-known surgery complications that may cause reductions in visual acuity ${ }^{(1,2)}$.

In recent years, transconjunctival sutureless vitrectomy (TSV) has been adopted as the preferred technique for vitreoretinal surgery. The advantages of sutureless small-gauge vitrectomy include technical simplicity, less traumatic conjunctival and scleral manipulation, shorter operative durations, less severe postoperative pain, and faster postoperative visual recovery ${ }^{(2,3)}$.

Several studies have demonstrated corneal changes induced by standard 20-G vitrectomy; however, few studies have investigated
23- and 25-G systems, with the majority finding minimal changes to corneal shape following 23- or 25-G vitrectomy compared with that in $20-\mathrm{G}$ vitrectomy $\mathrm{y}^{(2-5)}$.

This study aimed to evaluate and compare corneal topographic changes following pars plana vitrectomy (PPV) using 20-, 23-, and 25-G systems.

\section{METHODS}

The study protocol was approved by the Ethics Committee of the Hospital de Clinicas do Parana/Federal University of Parana. All patients were informed of the procedure and informed consent was obtained.

A prospective study was conducted on 57 consecutive patients (57 eyes) who underwent PPV at our institution. Indications for vitreoretinal surgery were rhegmatogenous retinal detachment,
Funding: No specific financial support was available for this study.

Disclosure of potential conflicts of interest: None of the authors have any potential conflict of interest to disclose.

Corresponding author: Alexandre Achille Grandinetti. Av. Vicente Machado - 1.171 - Curitiba, PR - 80420-011 - Brazil - E-mail: alexandregrandinetti@gmail.com

Project/CAAE: 01059412.5.0000.0096 - Hospital de Clínicas da UFPR. 
nonclearing vitreous hemorrhage, idiopathic epiretinal membrane, idiopathic macular hole, and vitreous opacities.

Patients with a history of corneal changes prior to surgery, such as rigid contact lens use, refractive surgery, cataract surgery, corneal trauma, corneal transplant, keratoconus, or corneal ulcers, were excluded from this study.

All patients underwent complete preoperative ophthalmic examinations including refraction, spectacle-corrected visual acuity, slit-lamp biomicroscopy, tonometry, and fundus examination by indirect ophthalmoscopy. All eyes were analyzed using computerized videokeratography (EyeSys 3000 Corneal Analysis System; version 3.4.0.0, Houston, TX, USA). Corneal topograpy was performed preoperatively and at one week, one month, and three months postoperatively. Measurements were performed at each follow-up visit, and topographic maps were analyzed. Analyses of corneal videokeratographs were performed using the Holladay Diagnostic Summary (HDS) software package. The HDS provides four color-coded maps and 15 corneal parameters providing information from the central $3 \mathrm{~mm}$ of the cornea. In this study, flat (K1) and steep (K2) meridians, mean keratometry power (mean K), and corneal astigmatism (K2-K1) were analyzed.

All surgeries were planned and performed by the same surgeon (AAG) from July 2013 to December 2013. The 57 included patients were assigned to three groups: Group 20-G, Group 23-G, and Group 25-G.

All patients underwent surgery with the use of the Constellation Vitrectomy Vision System (Alcon Laboratories, Fort Worth, TX, USA) and visualization of the fundus was made using the lens Volk MiniQuad $^{\circledR}$. The Group 20-G PPV was performed as a standard three-port PPV approach. The conjunctiva was opened $1 \mathrm{~mm}$ from the limbus, followed by three scleral incisions using a 20-G MVR blade (Sharp Point, USA) $4 \mathrm{~mm}$ from the limbus. Vitrectomy surgery was performed and all sclerotomies and conjunctiva were sutured at the end of the procedure with 7.0 vicryl. For the 23-G and 25-G groups, we used oblique-perpendicular sclerotomies by penetrating the displaced conjunctiva and sclera perpendicular to the limbus at an angle of $30-45^{\circ}$ to the sclera $4 \mathrm{~mm}$ posterior from the limbus. The conjunctiva was displaced with a atraumatic forceps and the microcannula were inserted with the Edge Plus blade (Alcon Laboratories Inc, Fort Worth, TX, USA). After vitrectomy, microcannulas were removed and sclerotomies covered by conjunctiva. In all groups, pars plana sclerotomies were performed at 2,8 and 10 o'clock (right eye) or at 2,4 and 10 o'clock (left eye). Postoperative treatment included a combination of moxifloxacin 0,5\% and dexamethasone 0,1\% (VIGADEXA $\left.{ }^{\circledR}\right)$ four times a day for 21 days.

IBM SPSS Statistics version 2.0 (IBM Corp, Armonk, NY, USA) was used for all statistical analyses. Preoperative and postoperative corneal topography measurement values were compared using the Student's t-test. Comparison of corneal parameters between groups was performed using the Fisher's exact test. Statistical differences with $P$-values less than 0.05 were considered significant.

\section{RESULTS}

Twelve patients were excluded from the study due to inability to cooperate with serial corneal topography or requirement of intraoperative sclerotomy site suturing as a result of persistent leakage following cannulae removal. Of the 45 patients, 24 were men and 21 were women. Twenty-five of the eyes were right and 20 were left. The mean age was 54.8 years \pm 12.6 (SD; range, 24-72 years). Patient demographics are summarized in table 1. No statistically significant differences in age, sex, or operated eyes were observed among the three groups.

Indications for vitreoretinal surgery were vitreous hemorrhage (20 eyes), due to diabetic retinopathy (18 eyes) or other causes (2 eyes), rhegmatogenous retinal detachment (11 eyes), idiopathic macular hole (3 eyes), vitreous opacities (6 eyes), and idiopathic epiretinal membrane (5 eyes)
The vitreous substitute most commonly used was air in 19 patients (42.2\%), followed by perfluoropropane gas (C3F8) in 16 patients (35.5\%), silicone oil in 6 patients (13.3\%), and balanced saline solution in 4 patients $(8.8 \%)$

During the postoperative period, an average steepening of 0.98 $\pm 0.18 \mathrm{D}$ in mean $K$ values was observed in the first postoperative week in group $1(P<0.001)$ with no significant difference observed in groups 2 and 3 . On postoperative day 30, an average steepening of $0.93 \pm 0.21 \mathrm{D}$ in mean $K$ values was observed in group $1(P<0.001)$ with no significant difference observed in groups 2 and 3 . On postoperative day 90, an average steepening of $0.09 \pm 0.13 \mathrm{D}$ in mean $K$ values was detected in group 1 , which was not clinically significant, as well as in groups 2 and 3. Keratometry measurements are shown on table 2.

No statistically significant differences in preoperative or postoperative visit measurements of corneal astigmatism were observed among the three groups analyzed. Figure 1 shows the variation in corneal astigmatism at all follow-up visits.

\section{DISCUSSION}

The advent of small gauge (23- and 25-G) instrumentation for PPV has allowed less invasive vitreoretinal surgery utilizing smaller sutureless incisions than with the conventional $20-\mathrm{G}$ system. As a result of these advances, vitreoretinal surgeons now have multiple choices when deciding on an operative approach ${ }^{(6)}$.

Wierbelauer et al. demonstrated a substantial increase in refractive corneal astigmatism and noted the occurrence of corneal topography changes following 20-G PPV, particularly in the immediate postoperative period ${ }^{(7)}$. Yanyali et al. evaluated the effect of sutureless 23-G PPV on corneal topography and concluded that corneal changes could be considered clinically insignificant ${ }^{(8)}$. Okamoto et al. also concluded that 25-G PPV does not induce significant changes in corneal topography with little influence on the optical quality of the cornea ${ }^{(3)}$.

In this study, we performed corneal topography using the EyeSys System 3000 topographer to evaluate corneal curvature changes following PPV with 20-, 23-, and 25-G systems. Our results demonstrate a statistically significant steepening of the central cornea 7 days after surgery with an average steepening of $0.98 \pm 0.18 \mathrm{D}$ observed in the 20-G PPV group $(P<0.001)$, whereas no statistically significant difference was observed in 23- and 25-G groups. Corneal steepening in the 20-G group persisted to 30 days following surgery with an average steepening of $0.93 \pm 0.21 \mathrm{D}(P<0.001)$ but returned to preoperative levels at 3 months after surgery with a difference of $0.09 \pm 0.13 \mathrm{D}$ $(P=0.604)$ compared with preoperative levels. In contrast, no statistically significant changes in corneal parameters were observed in 23- and 25-G groups on examination at 1 and 3 months after surgery.

Corneal surface dynamics and wound healing responses following PPV are affected by several factors, particularly relating to wound construction. These factors mostly relate to incisional sites. Suture-related factors are of considerable importance and include the placement and number of sutures, tensile strength, and suture materials. Other factors related to wound healing include wound edema, postoperative corticoid use, and thermal cautery ${ }^{(7,8)}$. Grandinetti et al. found significant corneal changes following 20-G PPV associated

Table 1. Patient demographics

\begin{tabular}{lccc}
\hline & Group 20-G & Group 23-G & Group 25-G \\
\hline$N$ & 15 & 15 & 15 \\
Mean age \pm SD (years) & $52.9 \pm 12$ & $57.7 \pm 11.2$ & $53.7 \pm 14.6$ \\
Sex (M:F) & $10: 5$ & $6: 9$ & $8: 7$ \\
Eyes (R:L) & $9: 6$ & $8: 7$ & $8: 7$ \\
\hline
\end{tabular}


Table 2. Simulated keratometry readings over time after pars plana vitrectomy (PPV)

\begin{tabular}{|c|c|c|c|c|c|c|c|c|c|c|}
\hline & \multirow[b]{2}{*}{$n$} & \multicolumn{3}{|c|}{ Group 20-G } & \multicolumn{3}{|c|}{ Group 23-G } & \multicolumn{3}{|c|}{ Group 25-G } \\
\hline & & $K 1$ & $K 2$ & Mean $K$ & $K 1$ & $K 2$ & Mean $K$ & $K 1$ & $K 2$ & Mean $K$ \\
\hline Pre op & 45 & $43.35 \pm 1.63 D^{*}$ & $45.13 \pm 1.00 D^{*}$ & $44.24 \pm 1.10 D^{*}$ & $43.62 \pm 1.44 \mathrm{D}$ & $44.23 \pm 1.52 \mathrm{D}$ & $43.93 \pm 1.45 \mathrm{D}$ & $42.70 \pm 2.27 \mathrm{D}$ & $44.18 \pm 2.30 \mathrm{D}$ & $43.44 \pm 2.13 \mathrm{D}$ \\
\hline 7 days & 45 & $44.30 \pm 1.64 D^{*}$ & $46.13 \pm 1.02 \mathrm{D}^{*}$ & $45.22 \pm 1.11 D^{*}$ & $44.02 \pm 1.47 \mathrm{D}$ & $44.67 \pm 1.55 \mathrm{D}$ & $44.34 \pm 1.48 \mathrm{D}$ & $42.77 \pm 2.27 \mathrm{D}$ & $44.23 \pm 2.27 \mathrm{D}$ & $43.50 \pm 2.11 \mathrm{D}$ \\
\hline 30 days & 45 & $44.26 \pm 1.61 D^{*}$ & $46.08 \pm 1.00 D^{*}$ & $45.17 \pm 1.09 D^{*}$ & $43.73 \pm 1.45 \mathrm{D}$ & $44.37 \pm 1.51 \mathrm{D}$ & $44.05 \pm 1.45 \mathrm{D}$ & $42.76 \pm 2.25 \mathrm{D}$ & $44.21 \pm 2.28 \mathrm{D}$ & $43.49 \pm 2.11 \mathrm{D}$ \\
\hline 90 days & 45 & $43.39 \pm 1.68 \mathrm{D}$ & $45.26 \pm 1.00 \mathrm{D}$ & $44.33 \pm 1.12 \mathrm{D}$ & $43.67 \pm 1.45 \mathrm{D}$ & $44.28 \pm 1.51 \mathrm{D}$ & $43.97 \pm 1.45 \mathrm{D}$ & $42.73 \pm 2.26 \mathrm{D}$ & $44.20 \pm 2.30 \mathrm{D}$ & $43.47 \pm 2.12 \mathrm{D}$ \\
\hline
\end{tabular}

${ }^{*}=P<0.05$ postoperative compared with preoperative values.

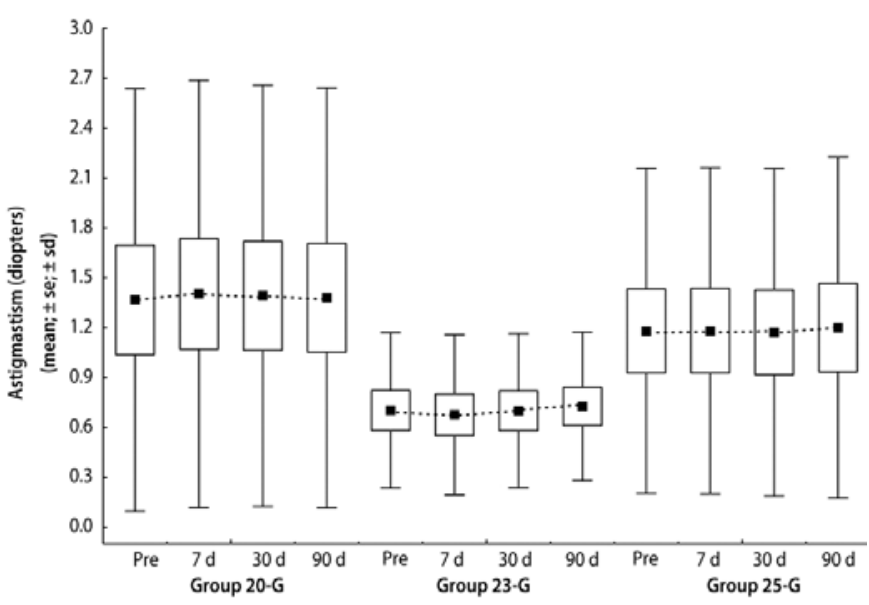

Figure 1. Variation in corneal astigmatism after pars plana vitrectomy (PPV).

with encircling scleral buckle surgery that returned to preoperative levels at 3 months following surgery, possibly owing to changes in scleral elasticity or loosening of sutures ${ }^{(9)}$.

Since the development of novel sutureless vitrectomy systems, several studies have been conducted to compare the degree of astigmatism induced by conventional 20-G PPV and sutureless 23- and 25-G techniques. This is the first study to include and compare all three techniques. We found no statistical difference in induced astigmatism levels among the three groups. Preoperative astigmatism levels were maintained in all groups during the first 3 months following surgery, despite the use of sutures and limited cautery in the 20-G group. This finding may be explained by the use of three incision locations, which may have counteracted corneal changes generated by individual incisional sites.

In conclusion, the findings of this study demonstrate TSV with 23and 25-G systems does not induce significant corneal topographic changes following surgery. However, we found 20-G PPV induces transient changes of the corneal curvature that persisted for 1 month following surgery before returning to preoperative levels 3 months after surgery.

\section{REFERENCES}

1. Domniz YY, Cahana M, Avni I. Corneal surface changes after pars plana vitrectomy and scleral buckling surgery. J Cataract Refract Surg. 2001;27(6):868-72.

2. Galway G, Drury B, Cronin BG, Bourke RD. A comparison of induced astigmatism in 20- vs 25-gauge vitrectomy procedures. Eye. 2010;24(2):315-7.

3. Okamoto F, Okamoto C, Sakata N, et al. Changes in corneal topography after 25-gauge transconjunctival sutureless vitrectomy versus after 20-gauge standard vitrectomy. Ophthalmology. 2007;114(12):2138-41.

4. Yanyali A, Celik E, Horozoglu F, Nohutcu AF. Corneal topographic changes after transconjunctival (25-gauge) sutureless vitrectomy. Am J Ophthalmol. 2005;140(5):939-41.

5. Park DH, Shin JP, Kim SY. Surgically induced astigmatism in combined phacoemulsification and vitrectomy; 23-gauge transconjunctival sutureless vitrectomy versus 20-gauge standard vitrectomy. Graefe's Arch Clin Exp Ophthalmol. 2009;247(10): 1331-7.

6. Spirn MJ. Comparison of 25, 23 and 20-gauge vitrectomy. Curr Opin Ophthalmol. 2009; 20(3):195-9.

7. Wirbelauer $\mathrm{C}$, Hoerauf $\mathrm{H}$, Roider J, Laqua $\mathrm{H}$. Corneal shape changes after pars plana vitrectomy. Graefe's Arch Clin Exp Ophthalmol. 1998:236(11):822-8.

8. Yanyali A, Horozoglu F, Macin A, et al. Corneal topographic changes after transconjunctival 23-gauge sutureless vitrectomy. Int Ophthalmol. 2011;31(4):277-82.

9. Grandinetti AA, Dias J, Trautwein AC, Iskorostenski N, Moreira L, Moreira ATR. Corneal topographic changes after 20-gauge pars plana vitrectomy associated with scleral buckling for the treatment of rhegmatogenous retinal detachment. Rev Bras Oftalmol. 2013;72:95-8. 